\title{
The Influence of Self-Efficacy Towards the Grit of Multidisciplinary Post-graduate Students
}

\author{
Mimbar Oktaviana \\ Postgraduate of Psychology \\ Airlangga University \\ Surabaya, Indonesia \\ oktavianamimbar@gmail.com
}

\begin{abstract}
The main purpose of this research was to know the effect of self-efficacy towards the multidisciplinary post-graduate students' grit. A grit is an encouragement that comes from within the individual in the form of persistence to attract and maintain the spirit to keep struggling in order to face the challenge for the achieving the goal. Students who have higher grit will more easily pass the obstacles in college. The sampling technique used in this study was on-probability sampling with incidental sampling technique. Incidental sampling technique was carried out with the consideration that the characteristics of the subject were difficult to find. The population in this study involved 38 multidisciplinary post-graduate students at fourth semester in graduate program of one university in Surabaya. The conclusion of this research was that self-efficacy has influence to the grit with medium category. One way to achieve success in college is by becoming a gritty student. A gritty student can be achieved by firstly increasing self-efficacy of the post-graduate students.
\end{abstract}

Keyword-Grit, multidisciplinary, postgraduate, self-efficacy

\section{INTRODUCTION}

Education is one of the important investments in facing the global future world. Therefore, education should be able to prepare $21^{\text {st }}$ century superior young generation, and be ready with the high competition to build country and the world. Continuing study to a higher level allows individuals to have hope of changing the future to be better than before. Another benefit that can be obtained from continuing education in college is skill improvement that can be used as a long-term investment, which is very useful for individual career development that later on will be followed by a better quality of life.

Students, in this context, are individuals who are studying at the level of college both on undergraduate, magister or doctor. Being a student is not easy since there are obstacles and challenges that will come from the beginning of the college to complete the education in college. The obstacles will be higher for multidisciplinary post-graduate students. Multidisciplinary post-graduate students are students who have completed an undergraduate education and then continue their education to a higher level with different majors from the one previously taken.
Obstacles that are experienced by multidisciplinary postgraduate students might come from within the individuals themselves or from outside the individuals that give bad impact from the delay of study to the failure of the study. To be able to pass the existed barriers, those students need to have a consistent and focused goal in order to be able to graduate on time with good score. On the other hand, those students need to have endurance in struggling in order not to give up when facing obstacles during the college, so they can finish their study on time.

According to the psychology, the consistency and endurance that are possessed by individuals also was called grit. The term grit appears firstly from the research that was conducted by [1]. Grit is a tendency to maintain persistence and spirit in trying to achieve challenging long-term goals, where people endure with many obstacles in order to achieve goals [1]. One of the most important determinants of individual success is grit, it takes hard work and focuses on one goal over the years or even decades to get the desired success [2]. According Paul (2016), if students with poor academic ability can work as well as students with higher academic skills, then there may be other academic achievement or persistence measures that can be more dominantly used in the study.

Individuals with higher grit levels can show a stronger drive than the average person. For high achievers, the extra encouragement provided by passion and flow is important, no matter what the field chosen to be engaged. [3] explains that grit can affect the outcome of performance especially when it is accompanied by high passion. However, it takes more will to endure and still adhere when facing big obstacles.

The results of recent research more showed that a person's achievement or success not obtained only with the model of academic ability, but also hard work in trying. Individuals who are more likely to work harder and longer and more likely to engage in intentional practices can improve the performance or success [4]. It is in line with the results of [5] study indicating that individuals with higher grit look less pleasant but more potentially better at learning methods when those individuals are confronted with obstacles such as when they have to learn to spell. 
Grit appears to predict the reactivity of the nervous system during challenging tasks [6]. Building grit, passion and persistence in achieving long-term goals can contribute to individual success [7]

Each student can have a high grit, and one way to get a high grit is to have confidence of the ability in the individual himself or herself. Students who have good self-esteem, have the confidence that they can face obstacles and they will be easier in completing college or finishing their study. Conversely, students with lack self-confidence in their abilities will experience difficulty through the obstacles they find in the college. It is supported by the results of Bouchard (2016) research showing that the perception of the selfefficacy is the appropriate variable construct for understanding performance, especially in academic tasks that require ongoing self-monitoring.

Social cognitive theory by Albert Bandura states that selfefficacy is an individual's belief and confidence to be able to coordinate and do something that is needed (manifested in the form of an action or job) in a situation and environment that exist around the individual (Bandura, 1995). The level of self efficacy determines how much effort will be shed and how long the individual will survive in facing obstacles or unpleasant experiences in the process of achieving the desired goal.

Self-efficacy and academic optimism are closely related to student performance and self-adjustment either directly or indirectly. They deal with class performance, stress, health, overall satisfaction and commitment to stay in school. Students with high self-efficacy is likely to help students by approach a situation that challenges anxiety or confusion or, more influential, in assisting students' psychological adjustments so that students can still complete their study [7]

In addition, Zimmerman (2000) says that high self-efficacy is associated with necessary behavioral characteristics for ongoing involvement in tasks or activities. For example, some studies that show that individuals with high self-efficacy are more likely to set goals, persistence in doing tasks, and utilize strategies for goal achievement. It happens because individual with higher self-efficacy have swift thinking [8]

Hsieh (2007) also states that students with regular selfefficacy are more likely to avoid a predetermined goal, whereas students who have higher self-efficacy prefer to achieve the goals made. Students with higher self-efficacy, in addition to preferring to achieve goals, also pay serious attention, organize, and collaborate effectively with their cognitive abilities [9]. Meanwhile, the individuals with high self-efficacy, will encourage themselves to enterprise and be diligent in doing business in order to achieve the desired goals. Conversely, those individuals with lower self-efficacy, will try to achieve the goal with the following feelings of doubt on the ability they have. If the individuals with low self-efficacy are faced with difficulties, it will slow down and decrease the effort, even surrender before the goal can be achieved. Therefore, it is not surprising that the students with higher self-efficacy has also been shown to predict the inmprovement of academic achievement [10]

\section{MethoD}

This study applied quantitative approach research type. Quantitative research is often required to use numbers, ranging from data collection, interpretation of the data and the presentation of the results [11] Based on data collection techniques, quantitative research is divided into three namely experiments, survey and non-reactive [12]. Based on data type and data collection techniques, this research used survey model. The survey method is quantitative research with a systematic study that asking the same questions to large numbers of people and then recording their answers [12].

The population in this study involved multidisciplinary post-graduate students of Magister Program at "X" State University in Surabaya who were taking their fourth semester with the number of students were 38 . The population used as a generalization of this research results has the following characteristics:

1) Post-graduate students of master program that is taking the fourth semester at State University of Surabaya.

2) The sexes of men or women are not distinguished, because all of them have equal opportunity to be the subject of this research.

3) The status of work is not distinguished. All students, who work or not, have equal opportunity to be the subject of research

4) Students whose S1 Study Program is not linear with S2 Study Program.

The amount of bigger samples will reflect an increasingly representative population [13]. The sampling used in this study was non-probability sampling with incidental sampling technique.

Sugiyono [14] explains that incidental sampling is a sample determination technique based on chance that anyone who by chance / incidental meet with the researcher can be taken as a sample or it can be seen by the person who happened to meet it in accordance with the required data source. The researcher used incidental sampling technique with the consideration that the characteristics of the subjects have no course schedule in the class so it was very difficult for the researcher to get the subject for sure.

This study used two psychological scales based on the variables studied namely grit scale and self-efficacy scale. The grit scale instrument was based on [1] with the consistency of interest dimension and the perseverance of effort. The selfefficacy scale instrument was made using Bandura theory with magnitude, strength and general dimension. Each scale had 5 alternative answers.

The scale test was given to the post-graduate students who were taking their second semester study at Airlangga University and State University of Surabaya, involving 151 students who were the subjects outside the actual research. The validity valued on each scale was between 0.33 until 0.59 on the grit scale and 0.34 until 0.4 on the self-efficacy scale. 
The value of the reliability test at each scale that was equal to 0.80 for grit scale and 0.75 for self-efficacy scale.

\section{RESULT AND DISCUSSION}

\section{A. Results of Data description}

The results of descriptive analysis aim at providing a description of the subject of research based on data from statistical results obtained from the group of subjects studied and not intended for testing the hypothesis. The following is the descriptive data in this research:

\begin{tabular}{ccccc}
\hline TABLE 1. & & & $\begin{array}{c}\text { Lowest } \\
\text { Score }\end{array}$ & Mean \\
SCORE & & Highest & & \\
RESULTED ON & Total & Score & & \\
GRIT SCALE & Item & & & \\
AND SELF- & & & & \\
EFFICACY & & & 30 & 39,12 \\
SCALE & & 55 & 20 & 34,82 \\
\hline Grit & 12 & 53 & \\
\hline Self-Efficacy & 10 & 43 &
\end{tabular}

The total item on the grit scale was 12 with the highest score of 55 and the lowest one was 30 . The self-efficacy scale has a total of 10 items with the highest score of 43 and the lowest score of 20 . The perceived social support scale has a total number of 12 with the highest score of 60 and the lowest score of 34. The categorization of scores on each scale was divided into three categories, namely high, medium and low category.

\section{B. Test Result Assumptions}

\section{1) Normality Test}

The data had a normal distribution if the value of probability or $\mathrm{p}>0.05$ then it can be said as normal distributed data. On the contrary, if value of $\mathrm{p}<0.05$, it can be said data were not normally distributed. Here is result of normality test in this research:

TABEL II. TEST RESULTS NORMALITY

\begin{tabular}{ccc}
\hline & Grit & Self-Efficacy \\
\cline { 2 - 3 } Asymp. Sig. (2-tailed) & 0,064 & 0,182 \\
\hline
\end{tabular}

Based on the result of normality test, it was known that the value of significance is 0,064 on grit and 0,182 in self efficacy. The value of the normality test results indicate that the significance score was greater than 0,05 , so it can be concluded that the data in this study were normally distributed and the assumption of normality test in this study was met.

Another method used for the normality test was to see the normal Probability Plot (P-P) of the Residual Standard Regression based on the distribution of data on the diagonal axis, on the basis of decision making as follows:

1) Normality assumptions are met when the data spread around the diagonal line and follow the diagonal line
2) The assumption of normality is not met if the data spread far from the diagonal line and unfollow the direction of the diagonal line

The normality test results in this study can be seen as follows:

\section{PICTURE 1. P-P PLOT}

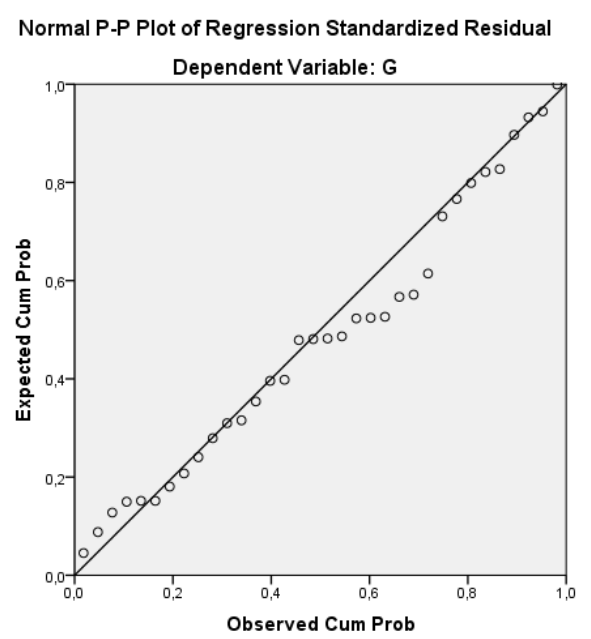

Based on the normality test using Probability Plot (P-P), it can be seen that the data spread around the diagonal line and follow the diagonal line from the lower left straight line to the upper right. The results on the Probability Plot (P-P) chart indicated that there was no large deviation from the normal line so that the data could be inferred normally distributed and satisfy the assumption of the normality test.

\section{2) Linearity Test}

Linearity test was done by using test of linearity with assumption. If the significance value $<0.05$, there is linear correlation between the independent variable and the dependent variable. Conversely, if the value of significance $>$ 0.05 , then there is no linear correlation between the independent variables and the dependent variables. Here is the result of linearity test in this research:

\section{TABLE III. RESULT OF LINEARITY TEST}

\begin{tabular}{cccc}
\hline Variabel & F & Sig. & Keterangan \\
\hline Linearity & 8,055 & 0,011 & Linear \\
\hline Deviation from linearity & 0,810 & 0,651 & \\
\hline
\end{tabular}

Based on linearity test results, the significance of the linearity value in the grit variable dealing with self-efficacy was 0.011 . The result of the significance of linearity showed that the value of significance was greater than 0.050 , so it could be interpreted that linearity assumption was fulfilled.

\section{3) Autocorrelation Test}

Autocorrelation test was conducted to determine the correlation between variables in the study. Autocorrelation can be determined by using Durbin Watson test. The values on Durbin Watson can be used to determine the assumption of 
whether or not residuals of multiple regression models are independent (no autocorrelation occurs). Autocorrelation does not occur if the value of Durbin Watson between -2 and 2 . Here are the results of autocorrelation tests conducted in this study

TABLE IV. RESULTS OF AUTOCORRELATION TESTS

\begin{tabular}{cc}
\hline Std. Error of the Estimate & Durbin-Watson \\
\hline 4,564 & 1,759 \\
\hline
\end{tabular}

Through the table above, it is known the Durbin-Watson value in this study was 1.759 . The value of the autocorrelation test results indicated that the Durbin-Watson value was greater than -2 and less than 2 , so it can be concluded that there was no autocorrelation.

\section{4) Multicollinearity Test}

Multicollinearity test is performed to test whether there is correlation between independent variables with dependent variable in multiple regression. In this study, multicollinearity test was done by looking at the value of Variance Inflation Factor (VIF). Multicolinearity does not occur if it meets assumptions if the values at tolerance value $>0,10$ and Variance Inflation Factor $(V I F)<10$. Here are the results of multicollinearity test in this study

TABEL V. RESULT OF MULTICOLINEARITY TEST

\begin{tabular}{ccc}
\hline Tolerance & VIF & Keterangan \\
\hline 0,973 & 1,027 & Tidak terjadi multikolinearitas \\
\hline
\end{tabular}

Based on multicollinearity test results, it was known that the variable tolerance value was 0.973 with VIF value of 1.027. The tolerance and VIF values on the multicollinearity test result showed that the tolerance value was more than 0.10 and the VIF value was less than 10 , so it can be concluded that there was multicollinearity between the variables in this study.

\section{5) Heteroscedasticity test}

The heteroscedasticity test aims at testing whether in a regression model there is a variance of residual data. To perform the test, it is done by using plot chart analysis between the value of the dependent variable with the residual. The assumption used in the heteroscedasticity test is that if the point in the graph is scattered and the not forms a pattern, it means that there is no heteroscedasticity. Here are the results of Heteroscedasticity test in this study:

\section{PICTURE 2. SCATTERPLOT}

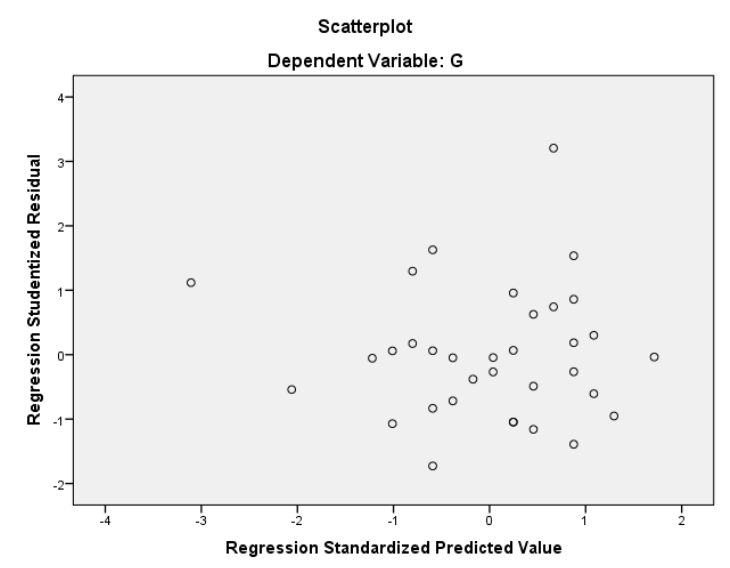

Based on the results of heteroscedasticity test in the Figure above, it can be seen that the dots or existing data does not form a regular pattern, so it is in accordance with the basic analysis of heteroscedasticity test which can be interpreted that in this study did not occur heteroscedasticity or in the regression function in this study did not appear unequal variant disruption

\section{Hypothesis Test Results}

1) t-test

T-test was done with the aim to know whether independent variable, self-efficacy, has a significant effect to the dependent variable namely grit. The testing was done by comparing the significance of each $t$ arithmetic on the independent variables with a significance level of 0.05 . If the significance value $<0,05$, then the variable affects the variable grit. Here is a table of t-test results in this study:

TABLE VI. t-TEST RESULT

\begin{tabular}{cccc}
\hline Variabel & Sig. & N & Information \\
\hline Self Efficacy & 0,010 & 34 & Have effect \\
\hline
\end{tabular}

Based on result of the t-test, it is known that the significance rate at self-efficacy variable equal to 0,010 , that value less than 0,05 , so it can be concluded that there was significant influence between self-efficacy variable to the grit.

2) The strength of the correlation between self-efficacy and grit

The strength of the correlation between independent variables i.e. self-efficacy towards the dependent variable, grit, can be known based on the following table:

TABLE VII. THE STRENGTH OF CORRELATION BETWEEN SELFEFFICACY AND GRIT

\begin{tabular}{cccc}
\hline $\mathbf{R}$ & R Square & $\mathbf{N}$ & Information \\
\hline 0,464 & 0,215 & 34 & Have Effect \\
\hline
\end{tabular}

Through the table, it was known that the value of $\mathrm{R}$ square coefficient was 0.215 and the $R$ value was 0.464 . $R$ square values explained that the self-efficacy contributes to grit variables of $21.8 \%$ and $78.2 \%$ that were influenced by other variables. The result of $\mathrm{R}$ result showed that the correlation between self-efficacy variable and the grit variable was in medium category.

\section{Model of Regression Equations}

$$
Y=21,927+0,494 X
$$

Through the model of multiple linear equations above, it can be seen that the constant value was 21.927. The constant value can be interpreted if self-efficacy variable was 0 . Hence, the influence of self-efficacy variable towards the grit variable was equal to 11.570. The self-efficacy variable had a regression coefficient value of 0.494 which could be 
interpreted if there was an increase of one unit in the variable of self-efficacy to other variables was assumed to be 0 , then the variable grit would change into 0.494 .

\section{E. Discussion}

The hypothesis test resulted in this study was that selfefficacy had an influence on multidisciplinary post-graduate students. In line with this study, a research conducted by Yusoff (2012) states that self-efficacy is likely to be higher in helping students approach challenging situations in anxiety or confusion. Students who have higher level of self-efficacy tend to have the confidence that they are able to solve the existing obstacles with the ability they have. Such result is in line with the study of Ahmad (2013) which found that the students with high self-efficacy got a higher score also on a difficult math test.

Self-confidence in self-abilities generally tends to assist individuals in facilitating goal setting, business investment, persistence in the face of obstacles, recovery from failure and emotional adaptation (Bandura, 1995; Poyrazli, McPherson, Arbona, Pisecco \& Nora, 2002: Schwarzer, 1992 ). The results of this study were also supported by the results of the research conducted by Chemers (2001) which states that, with a good self-efficacy, students are able to maintain a commitment to remain consistent with the goals and still struggling to achieve goals despite the number of obstacles that come.

\section{CONCLUSION}

This study concluded that the students who successfully completed the study well, despite the high challenges, was dealing with the influence of high level of self-efficacy they had. For students who had high self-efficacy would be aware of the supportive behaviors such as spirit and avoiding give up in completing difficult tasks, trying to solve tasks as well as the other possible problems. Conversely, for students who completed the study poorly, it was influenced by the behaviors that arose, the low self-efficacy they had. The low selfefficacy could be seen from the behaviors such as easily despair, frustration, only able to carry out easy behavior, feel the lack of support from the people around so that the consistency and student fighting spirit also became low.

The results of this hypothesis test can be applied to multidisciplinary postgraduate students to be able to improve their performance through grit improvement. Students can improve grit by the way, increasing their confidence in their abilities. Students who have high self-esteem in self-esteem will assist students in solving obstacles that come, students will be able to overcome obstacles without anxiety and confusion.

Based on research that had been done by researcher about the effect of self-efficacy toward the grit, the researcher advises the next researcher to a) deeper research on the grit and self-efficacy variables, b) conduct research using a larger number of subjects from this research in order to increase the depth of knowledge about the grit and self-efficacy variables and also develop the research by using other psychological attributes associated with grit.

\section{LIMITATIONS}

In carrying out this research, the researcher had limitations of the subject of research used in this study is limited to one university in Surabaya, considering that there are many universities in Surabaya, especially universities that have multidisciplinary post-graduate students. The results obtained will likely be different when it uses a greater number of research subjects with different characteristics among the research subjects.

\section{REFERENCES}

[1] A. L. Duckworth, C. Peterson, M. D. Matthews, and D. R. Kelly, "Grit: perseverance and passion for long-term goals.," J. Pers. Soc. Psychol., vol. 92, no. 6, p. 1087, 2007.

[2] A. Duckworth and J. J. Gross, "Self-control and grit: Related but separable determinants of success," Curr. Dir. Psychol. Sci., vol. 23, no. 5, pp. 319-325, 2014.

[3] M. J. De Vera, J. C. Gavino Jr, and E. J. Portugal, "Grit and superior work performance in an Asian context," in Proceedings of 11th International Business and Social Science Research Conference, January 2015, 2015.

[4] J. Resnik, "Do you have the GRIT to go the distance? We are proud to be a 2013 Premier Sponsor of the National Association of Women Lawyers," women lawyers journal, 98(3), 2013.

[5] A. L. Duckworth, T. A. Kirby, E. Tsukayama, H. Berstein, and K. A. Ericsson, "Deliberate practice spells success: Why grittier competitors triumph at the National Spelling Bee," Soc. Psychol. Personal. Sci., vol. 2, no. 2, pp. 174-181, 2011.

[6] P. J. Silvia, K. M. Eddington, R. E. Beaty, E. C. Nusbaum, and T. R. Kwapil, "Gritty people try harder: Grit and effort-related cardiac autonomic activity during an active coping challenge," Int. J. Psychophysiol., vol. 88, no. 2, pp. 200-205, 2013.

[7] L. E. Faust, "A Study of Grit and Self-Efficacy in Students in Developmental Placements," 2017.

[8] A. Zajacova, S. M. Lynch, and T. J. Espenshade, "Self-efficacy, stress, and academic success in college," Res. High. Educ., vol. 46, no. 6, pp. 677-706, 2005.

[9] D. H. Pintrich, P. R., \& Schunk, Motivation in education theory, research, and applications (2nd Edition). New Jersey: (P. E.-M. P. Hall, Ed.), 2002.

[10] I. S. Al-Harthy, C. A. Was, and R. M. Isaacson, "Goals, efficacy and metacognitive self-regulation a path analysis," Int. J. Educ., vol. 2, no. $1,2010$.

[11] J. W. Creswell, "Research Design (Pendekatan Kualitatif, Kuantitatif dan Mixed, Yogyakarta: Pustaka Pelajar,” Google Sch., 2010.

[12] W. L. Neuman, "Metodologi penelitian sosial: Pendekatan kualitatif dan kuantitatif," Jakarta PT. Indeks, 2013.

[13] F. N. Kerlinger and L. R. Simatupang, Asas-asas penelitian behavioral. Gadjah Mada University Press, 1990.

[14] Sugiyono, Metode Penelitian dan Pengembangan (Research and Development). Bandung: Alfabeta, 2017. 